\title{
Chance of psychiatric morbidity amongst recently diagnosed cancer outpatients attending a chemotherapy unit
}

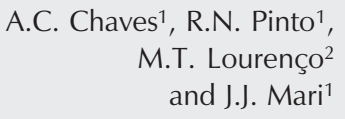

\author{
1Departamento de Psiquiatria, Escola Paulista de Medicina, \\ Universidade Federal de São Paulo, São Paulo, SP, Brasil \\ ${ }^{2}$ Hospital A.C. Camargo, São Paulo, SP, Brasil
}

\section{Correspondence \\ A.C. Chaves \\ Departamento de Psiquiatria EPM, UNIFESP \\ Rua Botucatu, 740, 3ㅇandar 04023-900 São Paulo, SP \\ Brasil \\ Fax: +55-11-5571-7254 \\ E-mail: chaves@psiquiatria.epm.br \\ Research supported by FAPESP (No. 99/06292-4). J.J. Mari is a CNPq researcher (I-A).}

Received November 19, 2004 Accepted April 26, 2005

\begin{abstract}
The prevalent rate of psychiatry morbidity amongst patients with cancer reported in various studies ranges from 5 to $50 \%$, a variation that can be attributed to differences in sample size, the disease itself and treatment factors. The objectives of the present study were to determine the frequency of psychiatric morbidity amongst recently diagnosed cancer outpatients and try to identify which factors might be related to further psychological distress. Two hundred and eleven (70.9\%) female patients and $87(29.1 \%)$ male patients from the chemotherapy unit of the Cancer Hospital A.C. Camargo (São Paulo) completed a questionnaire that featured data on demographic, medical and treatment details. The Self Reporting Questionnaire (SRQ-20) was administered to the patients to determine their personal psychiatric morbidity. Seventy-two patients (25.8\%) scored $\geq 8$ in the SRQ-20, the cut-off point for a patient to be considered a psychiatric case. When the low and high scoring groups were compared no differences were detected regarding age, marital status, tumor site, sex, or previous treatment. Nonetheless, patients in the lowest social class and those who were bedridden less than $50 \%$ of the time had a significantly higher probability of being a psychiatric case. Regarding helpseeking behavior in situations in which they had doubts or were frightened, about $64 \%$ of the total sample did not seek any type of support and did not talk to anyone. This frequency of psychiatric morbidity agrees with data from the cancer literature. According to many investigators, the early detection of a comorbid psychiatric disorder is crucial to relieve a patient's suffering.
\end{abstract}

The communication of the diagnosis of cancer to a patient is the beginning of a process involving experiences that could affect either the sick person himself/herself or the lives of members of his/her family. Psychological reactions to the diagnosis are fre-
Key words

- Psychiatric morbidity

- Cancer

- Chemotherapy

- Communication

- Psychological distress quent, but most patients pass through this acute phase and achieve a healthy level of adaptation (1). However, some develop clinically significant levels of psychological distress and require some form of treatment. The prevalent rates of psychiatric morbidity, 
as defined by various studies, range from 5 to $50 \%$ and this variation can be attributed to differences in sample size, the disease itself and treatment factors (1-3).

In Brazil, data in this area are scarce, but a study conducted by Citero et al. (4) with 319 cancer inpatients referred to the consultation-liaison psychiatry service of the Cancer Hospital A.C. Camargo in São Paulo city showed that, over a period of one year, 53\% of the referred patients required medication, $18.3 \%$ needed psychotherapy, $22.1 \%$ needed family intervention, and $20.5 \%$ needed guidance from the hospital's staff. To improve our understanding of this area, a cross-sectional study was conducted at the chemotherapy unit of the Cancer Hospital A.C. Carmargo located in the city of São Paulo, SP, Brazil. The main aim was to determine the frequency of psychiatric morbidity among recently diagnosed cancer outpatients and to investigate which factors might be related to greater psychological distress.

Recently diagnosed outpatients (less than 6 months) older than 18 years were included in the study. The study was submitted to and approved by the Ethics Committees of the Cancer Hospital A.C. Camargo and of Hospital São Paulo, Federal University of São Paulo. From October 1999 to April 2000 three investigators visited the chemotherapy unit daily in order to select patients.

The patients completed a socio-demographic questionnaire and the socio-economic classification was determined according to the criteria of the Brazilian Association of Market Research Institutes (ABIPEME) (5). The population was divided into categories ranging from A (best social level) to $\mathrm{E}$ (poorest social level). The degree of physical performance was evaluated using the Karnofsky Performance Scale (6) and the results ranged from 0 (capable of normal activity) to 4 (100\% bedridden). Patients were asked to complete two questionnaires, the Patient Information Questionnaire $(7,8)$ and the Self Reporting Questionnaire (SRQ-20) (9).
The SRQ was developed by the World Health Organization as a screening instrument to identify minor psychiatric disorders in primary care settings in developing countries (9). The questionnaire consists of 20 items scored in a binomial fashion $(0$, absence and 1, presence of a symptom). The validity coefficients of the Brazilian version of the SRQ were evaluated at three primary care units within the city of São Paulo, and the recommended cut-off point was 7/8 (10). In the present study, all questionnaires were read to the respondents, thus avoiding any misclassification bias related to a possible low educational level (11). Data were analyzed statistically by the chi-square test for categorical variables and by the Student $t$ test for continuous variables using the SPSS 8.0 package for Windows.

Participants signed an informed consent form and only 3 male patients refused to participate. The sample included 298 patients: 211 (70.9\%) women and $87(29.1 \%)$ men, all in chemotherapy treatment for different types of neoplasm. The mean age ( \pm SD) of the sample was $51.54 \pm 7.90$ years (range: 18-88 years). Seventy-two patients $(25.8 \%)$ scored $\geq 8$ on the SRQ-20, the cutoff point to be considered a psychiatric case. Table 1 shows the medical and social demographic characteristics of the sample with the probability of being a psychiatric case or not determined by the SRQ-20.

When the low and high scoring groups were compared, no differences were detected regarding age, marital status, tumor site, sex, or previous treatment. Nonetheless, patients in the lowest social class and those with level 2 Karnofsky performance (requires to be bedridden $<50 \%$ of the time) had a significantly higher probability of being a psychiatric case. The mean $( \pm$ SD) duration of treatment was $102.54 \pm 54.02$ days for psychiatric cases and $98.86 \pm 58.55$ days for non-psychiatric cases and this difference was not statistically significant. The mean $( \pm$ SD) total SRQ score for psychiatric cases 
was $11.04 \pm 2.49$ and $3.79 \pm 2.11$ for nonpsychiatric cases $(\mathrm{t}=24.3$; d.f. $=278 ; \mathrm{P}<$ $0.001)$.

The most frequent SRQ-20 items with a positive score for the total sample were: feeling nervous, tense or worried $(60.4 \%)$, unhappy (51.0\%) and easily tired (53.8\%); $41.0 \%$ complained about sleeping problems and $38.9 \%$ were crying more than usual. Seventeen items of the SRQ-20 were positive for more than $45 \%$ of the probable psychiatric cases; $91.0 \%$ of the probable psychiatric cases reported feeling nervous and tense, $90.3 \%$ feeling unhappy, $88.9 \%$ felt easily tired, and $75.0 \%$ were crying more than usual.

Table 2 shows the type of help sought when the patients felt doubts or were feeling frightened: about $64 \%$ of the sample did not seek any type of support and did not talk to anyone about their problems.

This was a cross-sectional study that set out to determine by the SRQ-20 the probability of a patient being a psychiatric case among recently diagnosed cancer outpatients and to investigate which factors might be related to increased psychological distress. The sample involved 298 outpatients in the initial stages of treatment and all with good physical performance status. Using the estimates provided by the Brazilian Ministry of Health for the year 2000, a comparison was made of the frequency of tumors in this sample and, except for the non-melanoma type of skin cancer in male and female patients and for prostate cancer in male patients, this sample can be considered to be representative of cancer patients regarding the tumor types occurring in Brazil (12).

To avoid sample selection bias, three investigators paid daily visits to the chemotherapy unit to select the patients and all medical records were checked to determine which patients met the inclusion criteria.

Seventy-two (26\%) patients satisfied the SRQ-20 criteria for being a psychiatric case, a result consistent with other studies on this

Table 1 Demographic and medical characteristics of the patients according to the probability of being or not being a psychiatric case in the Self Report Questionnaire20.

\begin{tabular}{|c|c|c|c|c|}
\hline & \multicolumn{2}{|c|}{$\begin{array}{c}\text { Probability of not being } \\
\text { a case }\end{array}$} & \multicolumn{2}{|c|}{$\begin{array}{c}\text { Probability of being } \\
\text { a case }\end{array}$} \\
\hline & $\mathrm{N}$ & $\%$ & $\mathrm{~N}$ & $\%$ \\
\hline \multicolumn{5}{|l|}{ Age } \\
\hline$<45$ years & 62 & 29.8 & 26 & 31.4 \\
\hline $46-55$ years & 57 & 27.4 & 17 & 23.6 \\
\hline $56-65$ years & 53 & 26.5 & 24 & 33.3 \\
\hline$>66$ years & 36 & 17.3 & 5 & 6.9 \\
\hline Total & 208 & 100 & 72 & 100 \\
\hline \multicolumn{5}{|l|}{$\chi^{2}=6.9,3$ d.f., $P=0.10$} \\
\hline \multicolumn{5}{|l|}{ Gender } \\
\hline Female & 143 & 69.1 & 57 & 79.2 \\
\hline Male & 65 & 30.9 & 15 & 20.8 \\
\hline Total & 208 & 100 & 72 & 100 \\
\hline \multicolumn{5}{|l|}{$\chi^{2}=2.8,1$ d.f., $P=0.09$} \\
\hline \multicolumn{5}{|l|}{ Social status } \\
\hline$A$ & 23 & 11.1 & 1 & 1.4 \\
\hline$B$ & 86 & 41.5 & 36 & 50.7 \\
\hline $\mathrm{C}$ & 72 & 34.8 & 22 & 31.0 \\
\hline $\mathrm{D}$ & 23 & 11.1 & 8 & 11.3 \\
\hline$E$ & 3 & 1.4 & 4 & 5.6 \\
\hline Total & 207 & 100 & 71 & 100 \\
\hline \multicolumn{5}{|l|}{$\chi^{2}=10.7,3$ d.f., $P=0.03$} \\
\hline \multicolumn{5}{|l|}{ Marital status } \\
\hline Single & 44 & 21.5 & 10 & 14.7 \\
\hline Married & 123 & 60.0 & 48 & 70.6 \\
\hline Divorced & 17 & 8.3 & 2 & 2.9 \\
\hline Widow & 21 & 10.2 & 8 & 11.8 \\
\hline Total & 205 & 100 & 68 & 100 \\
\hline \multicolumn{5}{|l|}{$\chi^{2}=43,3$ d.f., $P=0.23$} \\
\hline \multicolumn{5}{|l|}{ Residence } \\
\hline São Paulo city & 140 & 67.7 & 49 & 63.9 \\
\hline Greater São Paulo & 31 & 14.9 & 12 & 16.7 \\
\hline State of São Paulo & 25 & 12.0 & 6 & 11.2 \\
\hline Another Brazilian state & 12 & 5.6 & 6 & 8.3 \\
\hline Total & 208 & 100 & 72 & 100 \\
\hline \multicolumn{5}{|l|}{$\chi^{2}=0.78,3$ d.f., $P=0.85$} \\
\hline \multicolumn{5}{|l|}{ Tumor site } \\
\hline Breast & 78 & 37.7 & 27 & 37.5 \\
\hline Gastrointestinal & 37 & 17.9 & 12 & 17.6 \\
\hline Head and neck & 15 & 7.2 & 6 & 8.3 \\
\hline Hematological & 21 & 10.1 & 6 & 8.3 \\
\hline Lung & 18 & 8.7 & 10 & 13.9 \\
\hline Urogenital (female) & 17 & 8.2 & 4 & 5.6 \\
\hline Urogenital (male) & 6 & 2.9 & 2 & 2.8 \\
\hline Bone & 7 & 3.4 & 3 & 4.2 \\
\hline Other & 8 & 3.9 & 2 & 2.8 \\
\hline Total & 207 & 100 & 72 & 100 \\
\hline$\chi^{2}=2.5,8$ d.f., $\mathrm{P}=0.96$ & & & ued o & hext page \\
\hline
\end{tabular}


Table 1 continued.

\begin{tabular}{|c|c|c|c|c|}
\hline & \multicolumn{2}{|c|}{$\begin{array}{c}\text { Probability of not being } \\
\text { a case }\end{array}$} & \multicolumn{2}{|c|}{$\begin{array}{c}\text { Probability of being } \\
\text { a case }\end{array}$} \\
\hline & $\mathrm{N}$ & $\%$ & $\mathrm{~N}$ & $\%$ \\
\hline \multicolumn{5}{|l|}{ Performance status } \\
\hline Normal activity $(0)$ & 67 & 32.2 & 3 & 4.2 \\
\hline Some symptoms of disease (1) & 135 & 64.9 & 60 & 83.3 \\
\hline $\begin{array}{l}\text { Requires assistance less } \\
\text { than } 50 \% \text { bedridden ( } 2 \text { ) }\end{array}$ & 6 & 2.9 & 9 & 12.5 \\
\hline $\begin{array}{l}\text { Total } \\
\chi^{2}=28.6,2 \text { d.f., } P<0.000\end{array}$ & 208 & 100 & 72 & 100 \\
\hline \multicolumn{5}{|l|}{ Previous chemotherapy } \\
\hline Yes & 46 & 22.1 & 14 & 19.4 \\
\hline No & 162 & 77.9 & 58 & 80.6 \\
\hline $\begin{array}{l}\text { Total } \\
\chi^{2}=2.2,1 \text { d.f., } P=0.63\end{array}$ & 280 & 100 & 72 & 100 \\
\hline \multicolumn{5}{|l|}{ Previous surgery } \\
\hline Yes & 139 & 66.8 & 48 & 63.9 \\
\hline No & 69 & 33.2 & 26 & 36.1 \\
\hline $\begin{array}{l}\text { Total } \\
\chi^{2}=0.20,1 \text { d.f., } P=0.65\end{array}$ & 208 & 100 & 208 & 100 \\
\hline \multicolumn{5}{|l|}{ Previous radiotherapy } \\
\hline Yes & 28 & 13.5 & 14 & 19.4 \\
\hline No & 180 & 86.5 & 58 & 80.6 \\
\hline $\begin{array}{l}\text { Total } \\
\chi^{2}=1.5,1 \text { d.f., } P=0.22\end{array}$ & 208 & 100 & 72 & 100 \\
\hline
\end{tabular}

Table 2. Type of help sought by the patient for psychological support.

\begin{tabular}{lccc}
\hline $\begin{array}{l}\text { Type of help } \\
\text { sought }\end{array}$ & $\begin{array}{c}\text { Probability of not being } \\
\text { a case }(\mathrm{N}=208)\end{array}$ & $\begin{array}{c}\text { Probability of being } \\
\text { a case }(\mathrm{N}=72)\end{array}$ & $\begin{array}{c}\text { Total } \\
(\mathrm{N}=280)\end{array}$ \\
\hline Religion & 17.9 & 16.7 & 17.6 \\
Doctor & 29.3 & 27.8 & 28.9 \\
Family members & 36.2 & 47.2 & 39.1 \\
Friends & 17.9 & 15.3 & 17.2 \\
Did not seek any help & 62.8 & 69.4 & 64.5 \\
\hline
\end{tabular}

Data are reported as percent. There were no statistical differences between groups $\left(\chi^{2}\right.$ test). ing to these studies, the cut-off point for a patient to be a probable psychiatric case should be $7 / 8$, but in the present study the mean score on the SRQ-20 was 11.04 against 3.79 for non-psychiatric cases, and this difference was statistically significant $(\mathrm{t}=24.3$; d.f. $=278 ; \mathrm{P}<0.001)$.

One probable psychiatric case $(1.4 \%)$ was from the highest social class, $1.4 \%$ of the non-psychiatric cases were in the lowest social class, and since only 7 cases $(2.4 \%)$ were from the lowest social class, it was not possible to corroborate other studies that show an association between lower social class and greater psychological distress.

Patients with level 2 Karnofsky performance (requires to be bedridden less than $50 \%$ of the time) had a significantly higher probability of being a psychiatric case and this finding may well be related to the presence of physical symptoms in the SRQ-20. Nonetheless, in some studies, impaired physical activity, impaired social life (13) and pain (3) were found to be associated with both anxiety and depression in cancer patients.

More remarkable is that only less than $40 \%$ of the sample sought any type of support or talked to anyone about their feelings, doubts and fears. Thus, it is probable that, although $25.8 \%$ of patients might be considered a probable psychiatric case, they were not suffering enough psychological distress, or were not able to recognize the symptoms and to seek help for coping with their problems. The non-detection of co-morbid psychiatric disorders and psychological distress may worsen the patient's quality of life and increase the burden of the illness for the patient and his/her family (14). This is reflected by the increased number of studies concerning psychological intervention in cancer and also by the concern of most professionals caring for cancer patients $(15,16)$.

According to Fallowfield et al. (17), many of the psychological problems suffered by cancer patients could be prevented or at least 
ameliorated if the communication skills of the clinical staff were to be improved. However, there is no agreement in the current literature as to whether or not this is effective in improving the identification of patients at risk and as to which screening instruments are suitable for the detection of psychological morbidity in cancer patients $(18,19)$.

The present study showed that more than $25 \%$ of the outpatients with cancer in a chemotherapy unity in Brazil could be considered as probable psychiatric cases. The study did not evaluate the medical staff's ability to detect psychiatric morbidity, but found that only $30 \%$ of the patients talked to the doctor about their concerns regarding their feelings and fears. More studies in this area are necessary in order to clarify these issues.

\section{References}

1. Ford S, Lewis S \& Fallowfield L (1995). Psychological morbidity in newly referred patients with cancer. Journal of Psychosomatic Research, 39: 193-202.

2. Keller M, Sommerfeldt S, Fischer C et al. (2004). Recognition of distress and psychiatric morbidity in cancer patients: a multi-method approach. Annals of Oncology, 15: 1243-1249.

3. Atesci FC, Baltalarli B, Oguzhanoglu NK et al. (2004). Psychiatric morbidity among cancer patients and awareness of illness. Supportive Care in Cancer, 12: 161-167.

4. Citero VA, Nogueira-Martins LA, Lourenço MT et al. (2003). Clinical and demographic profile of cancer patients in a consultation-liasion psychiatric service. São Paulo Medical Journal, 121: 111-116.

5. De Felippe Jr B (1994). ABA/ABIPEME in Pesquisa: O Que É e Para Que Serve. Editora SEBRAE, Brasília, DF, Brazil, 30.

6. Karnofsky D, Abelmann W \& Craver L (1948). The use of the nitrogen mustards in the palliative treatment of carcinoma. Cancer, 1: $634-640$.

7. Meredith C, Symonds P, Webster L et al. (1996). Information needs of cancer patients in West Scotland: cross sectional survey of patients' views. British Medical Journal, 313: 724-726.

8. Pinto RN, Chaves AC, Lourenço MT et al. (2004). Information needs of recent cancer patients. International Journal of Psychiatry in Medicine, 34: 319-329.

9. World Health Organization - Division of Mental Health (1994). A User's Guide to the Self Reporting Questionnaire (SRQ). Brochure, WHO, Geneve, Switzerland.

10. Mari J \& Williams $P$ (1985). A comparison of the validity of two psychiatric screening questionnaires (GHQ-12 and SRQ-20) using relative operating characteristic (ROC) analysis. Psychological
Medicine, 15: 651-659.

11. Mari JJ \& Williams P (1986). A validity study of a psychiatric screening questionnaire (SRQ-20) in primary care in the city of São Paulo. British Journal of Psychiatry, 148: 23-26.

12. Ministério da Saúde-Brasil. Estimativa da incidência e mortalidade pelo câncer no Brasil. http://www.datasus.gov.br/. Accessed August 2000.

13. Aass N, Fosså SD, Dahl AA et al. (1997). Prevalence of anxiety and depression in cancer patients seen at the Norwegian radium hospital. European Journal of Cancer, 33: 1597-1604.

14. Newell S, Sanson-Fisher RW, Girgis A et al. (1998). How well do medical oncologists' perceptions reflect their patients' reported physical and psychosocial problems? Cancer, 83: 1640-1651.

15. Sheard T \& Maguire P (1999). Effects of psychosocial interventions on anxiety and depression in cancer patients: results of two metaanalyses. Bristish Journal of Cancer, 80: 1770-1780.

16. Arantzamendi $M$ \& Kearney $N$ (2004). The psychological needs of patients receiving chemotherapy: an exploration of nurse perceptions. European Journal of Cancer Care, 13: 23-31.

17. Fallowfield L, Ratcliffe D, Jenkins V et al. (2001). Psychiatric morbidity and its recognition by doctors in patients with cancer. British Journal of Cancer, 84: 1011-1015.

18. Hall A, Hern RA \& Fallowfield L (1999). Are we using appropriate self-report questionnaires for detecting anxiety and depression in women with early breast cancer? European Journal of Cancer, 35: 79-85.

19. Hopwood P, Howell A \& Maguire P (1991). Screening for psychiatric morbidity in patients with advanced breast cancer: validation of two self-report questionnaires. British Journal of Cancer, 64: 353-356. 